\title{
Tarlov Cysts: Endoscope-Assisted Obliteration of the Communication with the Spinal Subarachnoid Space
}

\author{
Juan Mezzadri ${ }^{1}$ Santiago Gonzalez Abbati ${ }^{1}$ Pablo Jalon ${ }^{1}$ \\ ${ }^{1}$ Department of Neurosurgery, Hospital de Clínicas, Buenos Aires, \\ Argentina \\ Address for correspondence Juan Mezzadri, MD, PhD, Department of \\ Neurosurgery, Hospital de Clínicas, Córdoba 2351, Buenos Aires 1120, \\ Argentina (e-mail: jmezzadri@intramed.net). \\ J Neurol Surg A 2014;75:462-466.
}

\begin{abstract}
Background and Objective The physiopathology of Tarlov or perineural cyst (PC) symptoms is unknown, but probably its filling and distention with spinal cerebrospinal fluid makes them symptomatic. The objective of this study is to describe the endoscopeassisted obliteration of the communication between PCs and the spinal subarachnoid space (SSS).

Patients and Methods From 2007 to 2011, four male and two female patients (median age: 45 years) with PCs were treated. They complained of lumbar, sciatic, and/or perineal pain. Physical examination was normal. The diagnosis was made by magnetic resonance imaging (MRI). All the cysts were located in the midline between S1 and S3. An endoscope-assisted obliteration between PC and SSS was performed. The outcome was evaluated clinically with the Odom scale and radiologically with an MRI. Results After a median follow-up of $\mathbf{2 5 . 8 3}$ months, the outcome was excellent (four cases), good (one case), and poor (one case). There were no complications. The postoperative MRI showed size and signal intensity changes in all PCs reflecting their

Keywords

- Tarlov cysts

- perineural cysts

- spine endoscopy exclusion from the SSS.

Conclusions The endoscope-assisted obliteration of the communication between PCs and the SSS is a simple technique that rendered excellent to good results in $83 \%$ of the cases.
\end{abstract}

\section{Introduction}

Tarlov cysts or perineural cysts (PC) were described in an autopsy in $1938 .{ }^{1}$ PCs are sacs filled with cerebrospinal fluid (CSF), formed within the posterior nerve root between the endoneurium and perineurium and distally to the ganglion. They are usually located in the sacral spine and have a variable communication with the spinal subarachnoid space (SSS) that causes their filling with CSF. Inside the cyst sac and/or its walls, nerve fibers and/or ganglion cells are located. ${ }^{2-4}$

Numerous theories have tried to explain their origin, and although it is believed that they are acquired, no theory has

received

January 6, 2013

accepted after revision

June 28, 2013

published online

March 28, 2014

fully demonstrated that. Most PCs are asymptomatic, and they are usually considered radiologic findings. Nowadays, the diagnosis is easily done with magnetic resonance imaging (MRI). The images show their typical morphological characteristics, allowing their differentiation from other spinal cysts. $^{2-4}$

Tarlov cysts have a prevalence of $1.5 \%$, but only $13 \%$ of them are symptomatic. ${ }^{5}$ This probably occurs when some of them fill and distend with CSF via the communication with the SSS.

The aim of the present study is to describe the endoscopeassisted obliteration of the communication between PCs and the SSS, and to analyze the outcome.

(c) 2014 Georg Thieme Verlag KG Stuttgart · New York
DOI http://dx.doi.org/ 10.1055/s-0033-1361836. ISSN 2193-6315. 

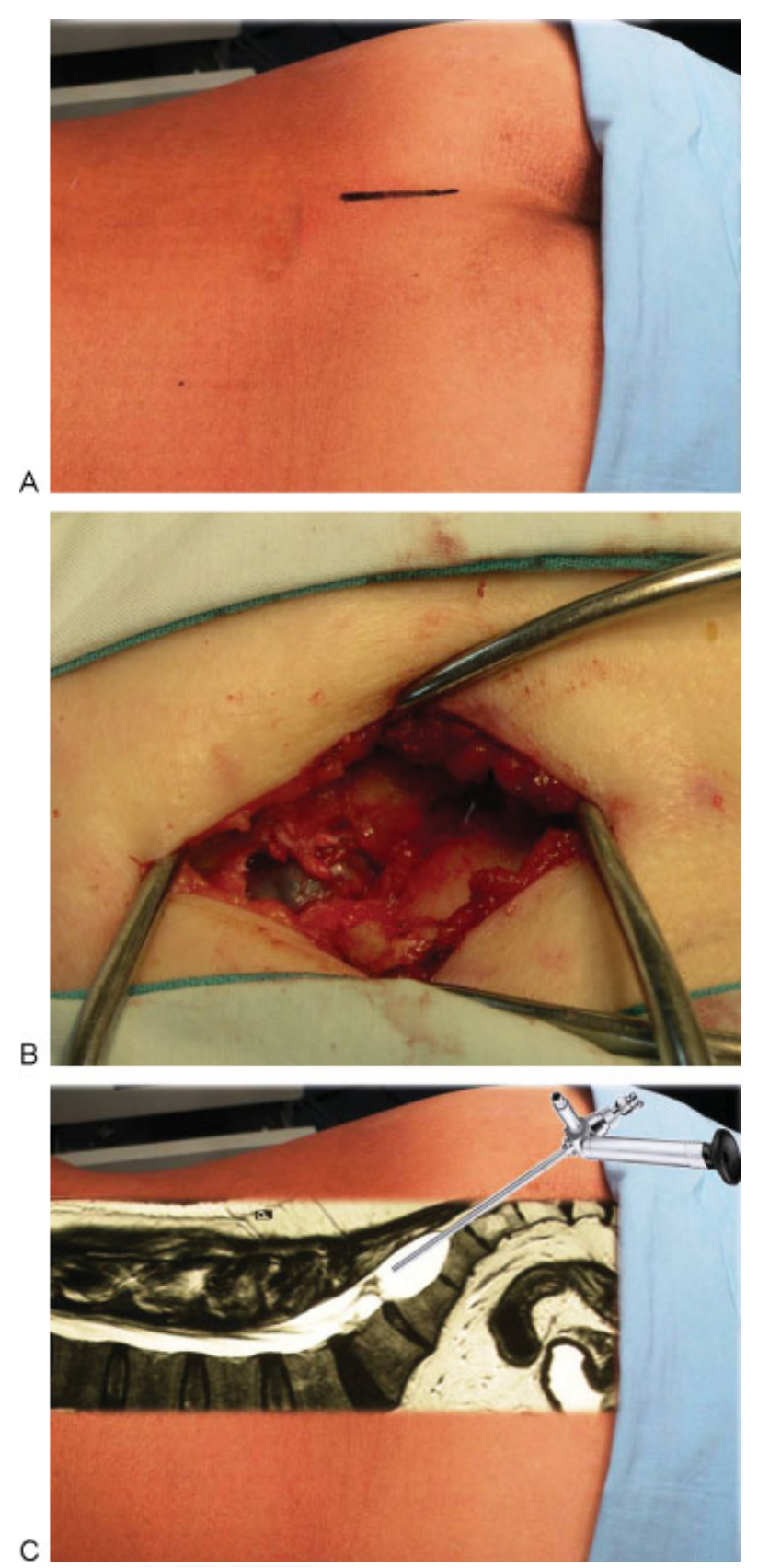

Fig. 1 (A) A 3-cm skin incision at the level of the caudal portion of the cyst. (B) Small sacral bone window and visualization of the pole of the cyst. (C) Entry point and direction of a rigid endoscope.

\section{Methods and Materials}

\section{Population}

Between 2007 and 2011, we treated six cases (four men and two women) with PCs. Ages ranged between 32 and 52 years (median: 45 years).

Patients complained of lumbar pain (six cases), sciatic pain (two cases), perineal pain (vaginal-perianal) (five cases), vesical tenesmus (one case), and/or rectal tenesmus (one case). The neurologic examination was normal in all cases. The pain increased in upright position and decreased in decubitus position.

\section{Diagnosis}

The diagnostic protocol included a neurologic, proctologic, urologic, and gynecologic examination and a lumbosacral MRI. The cysts were hypointense in T1-weighted images and hyperintense in T2-weighted images. Computed tomography (CT) scan was not used routinely. All cysts were located in the midline sacral spine, between $\mathrm{S} 1$ and S3, and were 4 to $7 \mathrm{~cm}$ in length and 2 to $3 \mathrm{~cm}$ in width.

\section{Endoscope-Assisted Surgery}

In these midline cysts, a 2- to 3-cm skin incision and a small sacral opening over the caudal portion of the cyst were performed. This allowed the introduction of a rigid endoscope with a 0 degree optic through the lower cyst pole (-Fig. $\mathbf{1}$ ).

A controlled and complete aspiration of the CSF from inside the cyst was performed to work with the endoscope in a dry field. Then, with a 30 to 45 -degree inclination and through the longitudinal axis of the cyst, the communication with the SSS was searched (-Fig. 2).

In some cases, the communication was difficult to see at a first glance because no CSF entered the cyst, and it was only possible to see the entry of the roots through the superior pole of the cyst ( $\mathbf{- F i g . 3}$ ). In these cases a Valsalva maneuver was performed. Then the CSF entered easily into the cyst, allowing the surgeon to see the communication. Once visualized, it was plugged with muscle, fat tissue, Gelfoam, and fibrin glue, completing the obliteration of the SSS. All cases had an external lumbar drain for 3 days postoperatively to assure the plugging.

\section{Evaluation}

Postoperative clinical outcome was measured with the Odom scale in four categories: excellent, good, fair, and poor. ${ }^{6}$ All PCs were controlled with a postoperative MRI.

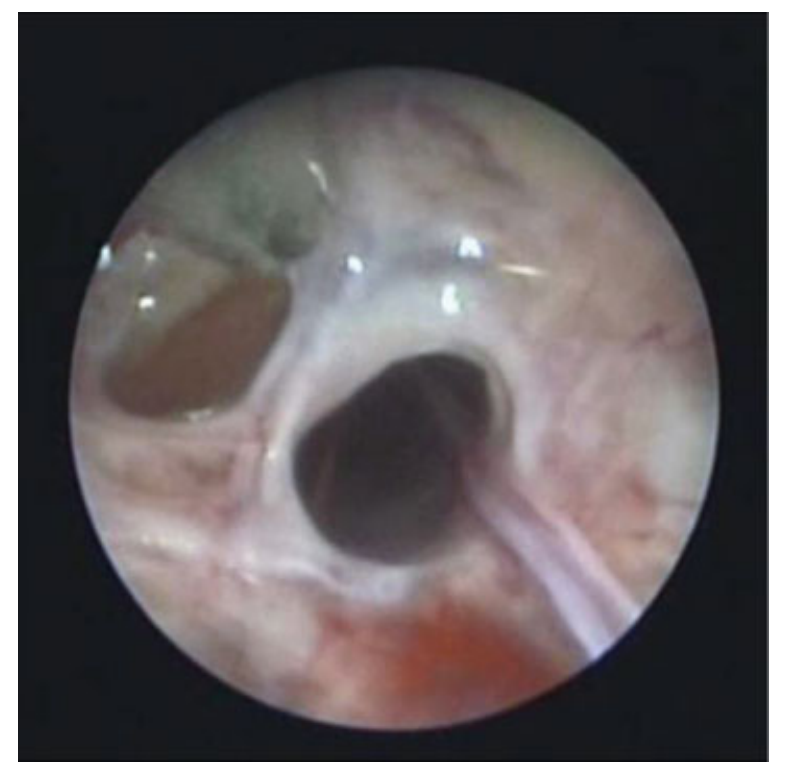

Fig. 2 Endoscopic view of the communication of the midline cyst with the spinal subarachnoid space. 


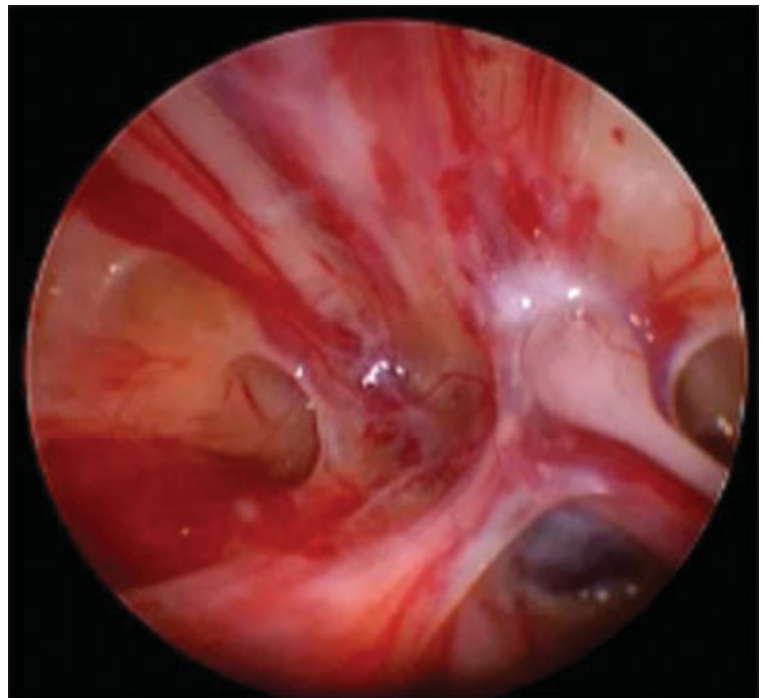

Fig. 3 Endoscopic view of the superior pole of the midline cyst with roots inside it and without a clearly identifiable communication.

\section{Results}

After a median follow-up of 25.8 months (9-52 months) the postoperative outcome of the six cases was excellent in four cases, good in one case, and poor in one case.

The postoperative MRI showed that the cysts did not disappear completely, but were reduced in size. Their intensity in T1- and T2-weighted images changed (-Figs. 4 and 5).

In the case with a poor outcome, the obliteration did not work, and after 30 days, the cyst was filling again with CSF seen in the MRI. The patient refused another procedure.

\section{Discussion}

Spinal meningeal cysts are usually classified into three types according to pathologic criteria. ${ }^{7}$ PCs or Tarlov cysts are considered type II cysts because they have roots inside of them. ${ }^{8}$

Because these midline cysts are bigger $(\geq 4 \mathrm{~cm})$, there is enough space to maneuver with the endoscope and, with a proper inclination, to find the communication with the SSS. In addition, because they were single, surgery can be performed only with one small opening in skin and bone, being much less invasive. This technique is not suitable for the more common bilateral PCs because it would be necessary to use more than one entry point. In addition, because they are smaller, there is not enough space to maneuver the endoscope in the cyst.

PCs usually contain only a few millimeters of CSF, but cysts containing up to 2.5 L have been described. ${ }^{9}$ The communication with the SSS is not always evident. All the cysts contained CSF, and once emptied at surgery, their filling was not immediate. In some cases the communication became visible only by increasing the CSF hydrostatic pressure with a Valsalva maneuver. This showed that cyst filling by a valve mechanism could be a sound theory in symptomatic cysts. $^{2-4}$

PCs are usually located in the sacrum. Rarely they are seen in other regions of the spine. They can erode the bony walls of the spinal canal as could be seen in some of our cases. Huge cysts can erode the sacrum leading to a fracture. ${ }^{2}$

Sometimes they may grow through a sacral foramen and expand in front of the sacrum and inside the pelvis, simulating adnexal masses in the echographic examination. ${ }^{10}$
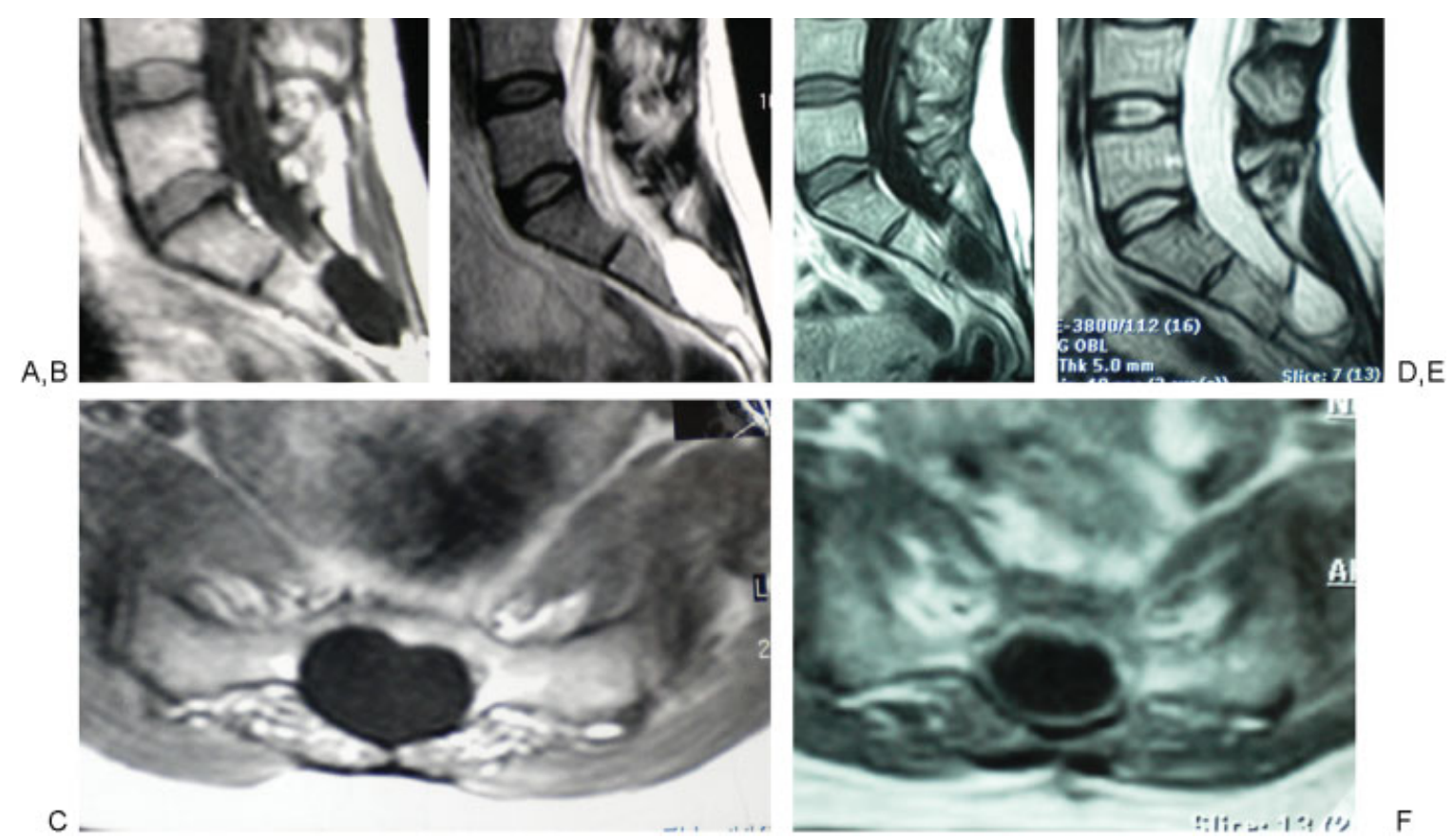

Fig. 4 Lumbosacral magnetic resonance imaging with a sacral cyst that shows (A) hypointensity in a T1-weighted sagittal image, (B) hyperintensity in a T2-weighted sagittal image, and (C) hypointensity in a T1-weighted axial image. Postoperative control shows cyst size changes in (D) T1-weighted sagittal image, (E) T2-weighted sagittal image, and (F) T1-weighted axial image. 


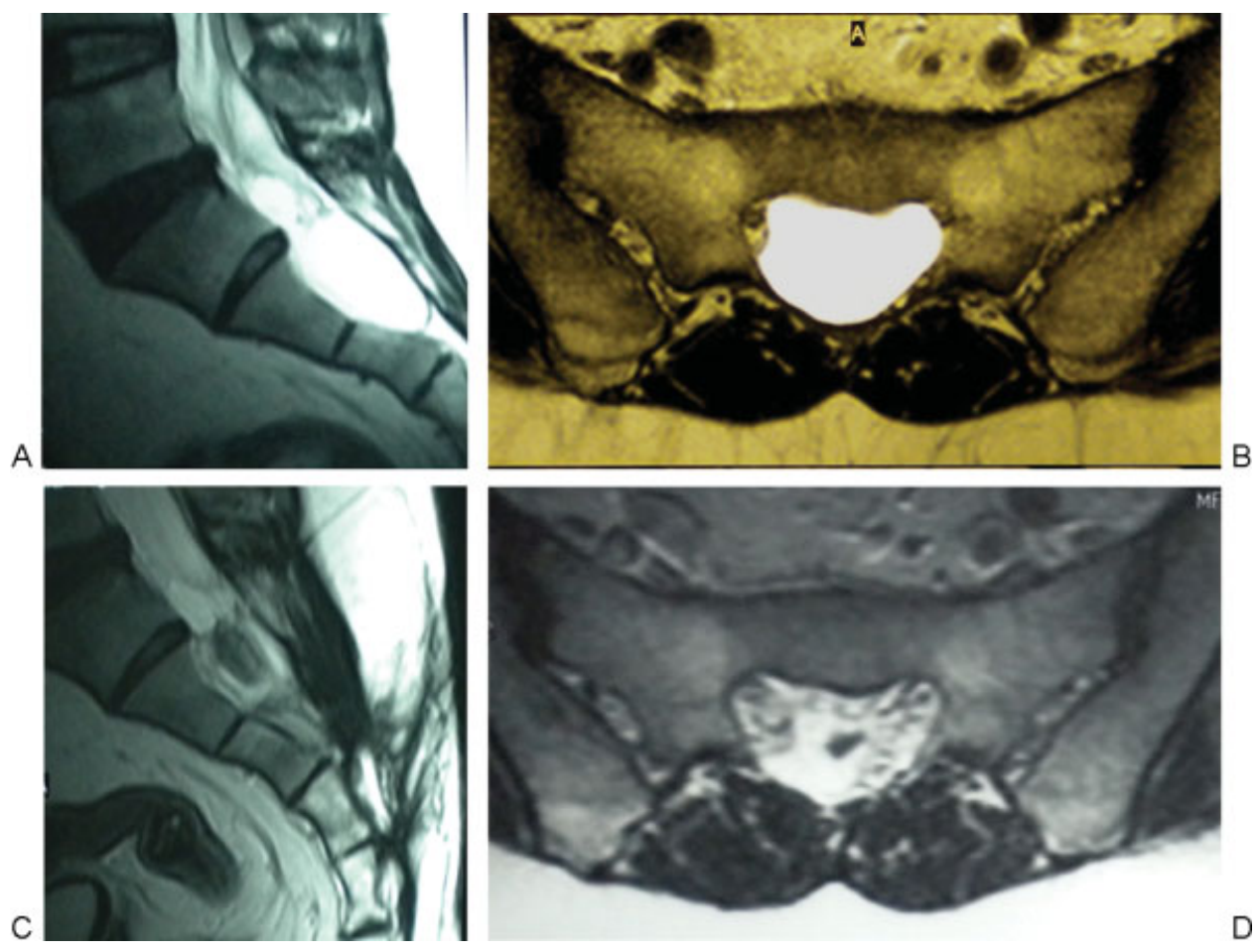

Fig. 5 Lumbosacral magnetic resonance imaging (MRI) with (A) preoperative hyperintensity in a T2-weighted sagittal image, (B) preoperative hyperintensity in a T2-weighted axial image, (C) postoperative changes in a T2-weighted sagittal image, and (D) postoperative changes in a T2weighted axial image.

As stated earlier, most PCs are asymptomatic; only $13 \%$ are symptomatic. ${ }^{5}$ Tarlov himself was the first to consider this possibility that most PCs are asymptomatic. ${ }^{11}$ Pain is the most frequent symptom, usually presenting as low back pain, sciatica, and/or coccygodynia. Perineal pain located in the vagina and/or anus is more characteristic; it may be associated with genital paresthesias. ${ }^{2}$ In large presacral cysts, the pain can be abdominal. ${ }^{9,10}$

When the cyst erodes the sacrum, the pain may be caused by a fracture. ${ }^{12}$ If the sacral fracture ruptures the cyst, fat tissue can penetrate the subarachnoid space, causing cerebral fat embolism and mental confusion. ${ }^{13}$

Frequently, patients also have dysfunctional bladder and/ or rectal symptoms: tenesmus, frequency, and /or incontinence. ${ }^{2,14}$ Sometimes, sexual dysfunctions such as dyspareunia or infertility can be present. ${ }^{4,15}$

The appearance of symptoms probably depends on the cyst size or its capability to compress nearby structures. Our cases had a size of at least $4 \mathrm{~cm}$. More than the size, the increased hydrostatic pressure in the cyst by CSF filling seems the more likely way how PCs compress adjacent structures and become symptomatic. This mechanism possibly explains why in some patients the pain increases when standing and decreases when lying.

Before assuming that PCs are responsible for the symptoms, the more common proctologic, urologic, and gynecologic pathologies and lumbar degenerative disc disease must be excluded by clinical and radiological examination. ${ }^{16}$

MRI is the gold standard for the diagnosis of PCs. ${ }^{5}$ They are located in the sacrum along the course of a nerve root and are of variable size, with an intensity similar to CSF. MRI allows to differentiate PCs from the other types of spinal cysts. $^{7,8}$

A thorough obliteration from the SSS is probably the best treatment for symptomatic PCs. ${ }^{14}$ By obliteration, PCs would not fill any longer with CSF, eliminating intracystal hydrostatic pressure increase and distension as well as compression of neighboring structures. However, the published therapeutic strategies are numerous, and each one has advantages and disadvantages.

When PCs are $\leq 1.5 \mathrm{~cm}$ in size, treatment with nonsteroidal anti-inflammatory drugs, steroids, amitriptyline, gabapentin, transcutaneous electrical stimulation, and/or a rehabilitation program can alleviate symptoms. ${ }^{17}$ Usually, surgery is performed in PCs $\geq 2 \mathrm{~cm}$ in size.

Total removal is possible, and the outcome reported has been favorable. ${ }^{8,11}$ However, because PCs contain nerve roots within or in their walls, total removal can cause neurologic deficits. That is why less invasive techniques have been developed: cyst opening with partial removal and wall plication, with or without using microsurgical techniques. ${ }^{18-20}$ Several times we tried to use these techniques, but the fragility of the PC walls precluded a safe closure. Therefore, we preferred cyst opening and plugging with fat and fibrin glue.

Percutaneous CSF aspiration and percutaneous injection of fibrin glue were reported as less invasive treatments. ${ }^{4,21}$ Both procedures only have a transient positive effect because the PCs fill with CSF again spontaneously and/or after fibrin glue absorption.

As an alternative minimally invasive technique, we used an endoscope-assisted obliteration with the SSS in a midline PC. A similar approach has not been reported before. There were 
no complications. The outcome after surgery was very favorable.

Recently, lumboperitoneal shunting was reported for symptomatic cases, with a favorable response after a follow-up of 3 months. ${ }^{22}$ However, in the long run, lumboperitoneal shunting leads to an acquired Chiari malformation in $30 \%$ of the cases, as a result of the pressure gradient. ${ }^{23,24}$ Lumboperitoneal shunting therefore seems to be an inferior surgical strategy to treat PCs.

\section{Conclusions}

The presented endoscope-assisted obliteration of the communication between the cysts and the SSS resulted in good to excellent outcomes and represents a simple and minimally invasive technique.

\section{References}

1 Tarlov IM. Cysts (perineurial) of the sacral roots; another cause, removable, of sciatic pain. J Am Med Assoc 1948;138(10):740-744

2 Acosta FL Jr, Quiñones-Hinojosa A, Schmidt MH, Weinstein PR. Diagnosis and management of sacral Tarlov cysts. Case report and review of the literature. Neurosurg Focus 2003;15(2):E15

3 De Sá MC, D’Angelo CT, Da Ros Malacarne G, Neto P, Pagura J. Tarlov's cyst: definition, etiopathogenesis, propaedeutic and treatment. [in Portuguese]. Acta Med Port 2008;21(2):171-178

4 Voyadzis JM, Henderson FC. Tarlov cysts. In: Benzel EC, ed. Spine Surgery: Techniques, Complications Avoidance, and Management. Philadelphia, PA: Elsevier; 2005:1124-1130

5 Langdown AJ, Grundy JR, Birch NC. The clinical relevance of Tarlov cysts. J Spinal Disord Tech 2005;18(1):29-33

6 Odom GL, Finney W, Woodhall B. Cervical disc lesions. JAMA 1958; 166:23-28

7 Nabors MW, Pait TG, Byrd EB, et al. Updated assessment and current classification of spinal meningeal cysts. J Neurosurg 1988; 68(3):366-377

8 Tarlov IM. Spinal perineurial and meningeal cysts. J Neurol Neurosurg Psychiatry 1970;33(6):833-843

9 Ishii K, Yuzurihara M, Asamoto S, Doi H, Kubota M. A huge presacral Tarlov cyst. Case report. J Neurosurg Spine 2007;7(2):259-263
10 H'ng MWC, Wanigasiri UIDK, Ong CL. Perineural (Tarlov) cysts mimicking adnexal masses: a report of three cases. Ultrasound Obstet Gynecol 2009;34(2):230-233

11 Tarlov IM. Perineural cysts of the spinal nerve roots. Arch Neurol Psychiatry 1938;40:1067-1074

12 Peh WC, Evans NS. Tarlov cysts-another cause of sacral insufficiency fractures? Clin Radiol 1992;46(5):329-330

13 Duja CM, Berna C, Kremer S, Géronimus C, Kopferschmitt J, Bilbault P. Confusion after spine injury: cerebral fat embolism after traumatic rupture of a Tarlov cyst: case report. BMC Emerg Med 2010; 10:18

14 Ruibal Moldes M, Sánchez Rodríguez-Losada J, López García D, Casas Agudo V, Janeiro País JM, González Martín M. Tarlov cyst and symptomatic bladder disfunction. [in Spanish]. Actas Urol Esp 2008;32(10):1035-1036

15 Singh PK, Singh VK, Azam A, Gupta S. Tarlov cyst and infertility. J Spinal Cord Med 2009;32(2):191-197

16 Mezzadri J. Lumbar and cervical pain of discal origin. In: Micheli $\mathrm{F}$ et al, eds. Tratado de Neurología Clínica [in Spanish]. Buenos Aires, Argentina: Editorial Médica Panamericana; 2002:185-208

17 Avellanet M, Sáenz A, Mirapeix RM, et al. Tarlov cysts: three symptomatic cases. [in Spanish]. Rehabilitación (Madr) 2004; 38:250-253

18 Caspar W, Papavero L, Nabhan A, Loew C, Ahlhelm F. Microsurgical excision of symptomatic sacral perineurial cysts: a study of 15 cases. Surg Neurol 2003;59(2):101-105; discussion 105-106

19 Mummaneni PV, Pitts LH, McCormack BM, Corroo JM, Weinstein PR. Microsurgical treatment of symptomatic sacral Tarlov cysts. Neurosurgery 2000;47(1):74-78; discussion 78-79

20 Park HJ, Kim IS, Lee SW, Son BC. Two cases of symptomatic perineural cysts (Tarlov cysts) in one family: a case report. J Korean Neurosurg Soc 2008;44(3):174-177

21 Patel MR, Louie W, Rachlin J. Percutaneous fibrin glue therapy of meningeal cysts of the sacral spine. AJR Am J Roentgenol 1997; 168(2):367-370

22 Cure GC, Fonnegra Caballero A, Diez JC, et al. Lumboperitoneal shunt for treatment of symptomatic lumbar Tarlov cysts. [in Spanish]. Rev Chil Neurocirugía 2009;33:34-38

23 Karabatsou K, Quigley G, Buxton N, Foy P, Mallucci C. Lumboperitoneal shunts: are the complications acceptable? Acta Neurochir (Wien) 2004;146(11):1193-1197

24 Wang MY, Levi AD, Green BA. Intradural spinal arachnoid cysts in adults. Surg Neurol 2003;60(1):49-55; discussion 55-56 